\title{
CONSTRUCCIÓN DE UNA ETIOLOGÍA DE LA VIOLACIÓN EN LOS DISCURSOS DE LA MEDICINA LEGAL Y LA CRIMINOLOGÍA CHILENA (1900-1950)*
}

\author{
CONSTRUCTION OF AN ETIOLOGY OF RAPE THROUGH \\ THE DISCOURSES OF LEGAL MEDICINE AND CHILEAN \\ CRIMINOLOGY (1900-1950)
}

\section{ALEJANDRA PALAFOX MENEGAZZI**}

Resumen: En el presente artículo abordamos la construcción de una etiología de la violación en el ámbito de la Medicina Legal y la Criminología, durante la primera mitad del siglo XX en Chile. Planteamos la hipótesis de que en el proceso aludido se reforzó un determinismo biológico y social, articulado, en parte, a través de la naturalización de la violencia sexual masculina perpetrada contra mujeres, así como de su asociación con determinados grupos sociales. Mediante el análisis discursivo de monografías, obras didácticas y artículos, comprobamos cómo, en función de las circunstancias, la comisión de esta tipología delictiva fue asimilada dentro de la confluencia de dos tendencias interpretativas, compatibles y, a la vez, no exentas de contradicciones. En este sentido, la violación fue interpretada como la materialización de una psicopatología asociada a las categorías de perversión y demencia, al tiempo que concebida como expresión de una transversal, natural e instintiva inclinación varonil hacia el ejercicio de una sexualidad violenta. Consideramos que lo afirmado fue el resultado de la interacción entre conceptualizaciones ideológicas socioétnicas y de género con una particular reformulación de determinados referentes teóricos, asentados en la criminología positivista finisecular europea.

Palabras Clave: Violación, determinismo, perversión, medicina legal, criminología.

ABSTRACT: In this article we address the construction of an etiology of rape, from the field of Legal Medicine and Criminology, during the first half of the 20th century in Chile. We hypothesize that in the aforementioned process a biological and social determinism was reinforced, articulated, in part, through the naturalization of male sexual violence perpetrated against women, as well as its association with certain social groups. Through the discursive analysis of monographs, didactic works and articles, we verify how, depending on the circumstances, the commission of this criminal typology was assimilated within the confluence of two interpretative tendencies, compatible and, at the same time, not exempt from contradictions. In this sense, rape was interpreted as

* Financiación del Proyecto de Postdoctorado ANID Fondecyt n. 3180184.

** Doctora en Historia. Académica de la Universidad Autónoma de Chile, Santiago, Chile. Grupo de Investigación Estudios Históricos sobre Cultura Científica. Correo electrónico: alejandra.palafox@ uautonoma.cl. Orcid: https://orcid.org/0000-0003-1936-5432. 
the materialization of a psychopathology associated with the categories of perversion and dementia, while conceived as an expression of a transversal, natural and instinctive male inclination towards the exercise of violent sexuality. We consider that it was the result of the interaction between socio-ethnic and gender ideological conceptualizations with a particular reformulation of certain theoretical references, based on the European fin-century positivist criminology.

Keywords: Rape, Determinism, Perversion, Legal Medicine, Criminology.

Recibido: 01.12.2020. Aceptado 01.04.2021.

\section{INTRODUCCIÓN}

L

A EXTRAORDINARIA ACOGIDA y adaptación del positivismo criminológico europeo a la realidad chilena durante la primera mitad del siglo XX (Carnevali, 2008) se dejó sentir desde inicios de la centuria en las discusiones acerca de la necesidad de implementar un sistema efectivo de prevención y control de la delincuencia, así como en la construcción de discursos etiológicos, orientados a desentrañar, científicamente, las causas de la comisión delictiva. Dentro de este complejo y heterogéneo proceso, junto con la criminología positivista -disciplina que se legitimó durante este periodo como "ciencia causal explicativa" del delito y el delincuente (Del Olmo, 2010, p. 155), la Medicina Legal, como ciencia auxiliar en formación, tuvo una participación decisiva, ligada a la determinación de las capacidades mentales de los acusados, incluida entre sus funciones (Palafox, 2020).

En este marco, junto con la comprensión del delincuente como un ser anormal y mentalmente patologizado, se fue imponiendo la imagen de un individuo criminalmente determinado por su interacción con un ambiente pernicioso, dentro de una progresiva complejización del estudio del delincuente que, desde finales de 1930, estuvo orientada a desarrollar su conocimiento integral y a determinar su peligrosidad, mediante exámenes que permitieran vislumbrar la articulación de los factores individuales y ambientales en la etiología delictiva y cuyos resultados fueron ordenados en "fichas criminológicas" (León, 2008). A partir de la segunda mitad del periodo, además, la promoción de una sexualidad heterocentrada adquirió un papel protagónico en la esfera pública del país, en un particular contexto nacionalista ligado a un malestar creciente y canalizado por las emergentes clases medias, ante la irresuelta "cuestión social", en el que se desarrollaron diversos programas institucionales de corte higienista y eugénico, caracterizados por querer mejorar la condición biológica de la población (Durán, 2014; Sánchez, 2015; Labarca, 2008; Vetö, 2015; Vetö 2018). 
Ante la situación descrita, buscamos conocer de qué manera los factores individuales -orgánicos y psicológicos- y ambientales estuvieron relacionados en la conformación de una etiología de la violación, delito tipificado en la codificación penal de 1874 como el acceso a una mujer mediante el uso de la fuerza o intimidación, cuando la víctima se hallase privada de sentido o razón o cuando esta fuera menor de doce años ${ }^{1}$. Frente a esta conceptualización, nos preguntamos cuáles fueron las apreciaciones específicas y compartidas sobre las agresiones referidas, considerando que su significación sobrepasó lo estipulado en el ámbito legal, coadyuvando a la elaboración de una construcción cultural del cuerpo sexuado (Bourke, 2009).

Para ello, analizamos un corpus documental amplio -compuesto por monografías, obras didácticas y artículos publicados en la Revista de ciencias penales, principal órgano de difusión de las investigaciones impulsadas desde la Dirección General de Prisiones y el Instituto de Criminología. En nuestro análisis consideramos el discurso como elemento activo en la creación de significados y en la conformación de las relaciones sociales (Antaki y Condor, 2000). En relación con lo afirmado, interpretamos el corpus referido como parte de una semántica científica que, pese a estar dirigida a un público especializado, nació con el afán de sobrepasar su propio ámbito para insertarse en otras áreas socioculturales, de acuerdo con las dinámicas adoptadas por la ciencia en la época (Bowler y Morus, 2005), coadyuvando, así, a la creación de un sentido común (León, 2018, p. 139), no exento de prejuicios deterministas (Vetö, 2014). Al respecto, concebimos la Medicina Legal y la Criminología como campos científicos imbricados, productores de un conocimiento ficticiamente neutro (Bourdieu, 2008, pp. 12-23 y 47) y como sistemas de significación, ahondando en algunas de sus prácticas discursivas, con objeto de conocer de qué manera la construcción de la "violación", como categoría sociocultural, contribuyó a la "realización" de lo masculino y lo femenino, comprendidos como categorías de género normativas y con pretensión ontológica (Butler, 2007, p. 29).

Durante nuestro análisis, advertimos cómo el afán científico por conceptualizar, conocer y desentrañar las causas de la violación fue abordado de forma tangencial, inserto, en la mayor parte de los casos, en un proceso

\footnotetext{
${ }^{1}$ Hasta la reforma penal de 1999, esta tipificación jurídico normativa se encontró dentro de la categoría de "Crímenes y simples delitos contra el orden de las familias y contra la moralidad pública", al ser estos los bienes jurídicos contra los que, formalmente, se atentaba (Palafox, 2020, p. 126). Solo las mujeres podían ser víctimas y solo los varones victimarios de un delito de violación. La violencia sexual entre varones quedó enmarcada penalmente dentro del delito de sodomía (Palafox, 2020).
} 
mayor de acercamiento al crimen y a la sexualidad, dentro del cual estas agresiones ocuparon un espacio reducido. Consideramos que esta situación se debió, por un lado, a una naturalización de la violencia sexual como factor esencialmente varonil, lo que la hacía aparecer como irremediable. El proceso aludido apareció, además, unido a la pervivencia, dentro del imaginario hegemónico de algunos de los autores consultados, de la violación como un delito sobredimensionado -ligado a la afluencia de falsas acusaciones femeninas- $y$ de su asociación con una otredad, simbolizada por los sectores populares.

La autoridad de los espacios de producción desde los que se elaboraron estas construcciones científicas supuso la validación académica de un determinado orden sexual, así como de viejos prejuicios sociales -étnicos, de clase y de género-, que fueron reformulados como neutrales desde una pretendida objetividad. Ante esta situación, buscamos conocer de qué manera la virilidad -comprendida como "mandato de género transversal a los grupos sociales", articulado sobre el deseo sexual y la agresividad como factores biológicos (González, 2007, p. 187)- se enlazó con las variables aludidas.

\section{ALGUNOS REFERENTES TEÓRICOS}

La conceptualización del instinto como una fuerza dirigida hacia la cópula heterosexual -concebida como normal y natural- pero que sobrepasaba este objeto, atravesando todo el organismo y la conducta humana y pudiendo presentar, así, anomalías constitutivas y adquiridas, fue ya desarrollada a mediados del siglo XIX por el psiquiatra ruso Heinrich Kaan (1816-1893), (Archimio, 2018). Sin embargo, su complejización y popularización en el ámbito occidental no se produjo sino hasta la década de 1880, de la mano, principalmente, del austro-alemán Richard von Krafft-Ebing (1840-1902), dentro de la proliferación de estudios psiquiátricos que concebían el instinto sexual en términos funcionales, como una fuerza independiente de la estructura de los órganos genitales, que se podía ver alterado -disminuido, aumentado o pervertido- por razones psíquicas concretas (Davidson, 2004).

Esta conceptualización, dentro de un proceso de apropiación científica y medicalización de la sexualidad, convivió con la afluencia de explicaciones organicistas sobre la etiología de los comportamientos sexuales (Beccalossi, 2012), además de promover la anormalización patológica de aquellas conductas sexuales no orientadas a la procreación. Para ello, resul- 
tó operativa la categoría de "perversión moral de los instintos", que aludía a alteraciones psicológicas, pero también fisiológicas, tachadas de anormales -por no buscar ni posibilitar con ellas la reproducción humana- y que fue enmarcada dentro de una particular reconfiguración de la teoría de la degeneración (Huertas, 1990, p. 90). Originado en la obra publicada en 1857 por Bénédict Morel (1809-1873), el concepto de "degeneración" fue empleado para interpretar que las anomalías conductuales - morales e intelectuales- guardaban su origen en una supuesta constitución orgánica anormal, heredable, incorregible, condenada a una decadencia progresiva y materializada en términos somáticos y fisiológicos perceptibles (Sánchez, 2014).

La articulación de la teoría de Morel con el evolucionismo darwinista propugnado por Valentín Magnan dio como resultado la creación del degeneracionismo como "paradigma de la psiquiatría" (Campos, 2013, p. 2), dentro del cual la perversión sexual aparecía como una enfermedad fruto de una alteración anatomofisiológica, residente en el sistema nervioso central de quienes la padecían (Huertas, 1990).

En el ámbito criminológico, dentro del afán positivista por comprender científicamente la etiología del comportamiento humano, la particular recepción y reelaboración de la teoría de la degeneración y del evolucionismo darwinista por parte del psiquiatra veronés Cesare Lombroso, fundador de la escuela de Antropología Criminal Italiana, dio como resultado el desarrollo de múltiples trabajos orientados a constatar la existencia del llamado "criminal nato", individuo cuyos caracteres orgánicos regresivos, causados por un proceso de degeneración, lo hacían biológicamente determinado para la comisión delictiva (Gibson y Rafter, 2006, p. 11).

En relación con las agresiones sexuales masculinas, Lombroso articuló dos categorías delictivas: el violador "ocasional" y el "nato", dibujando a este último como un loco moral, es decir, un individuo con plenas facultades mentales, pero incapaz de distinguir entre el bien y el mal, a causa de un proceso degenerativo hereditario y perceptible fisiognómicamente (Palafox, 2019). Esta figura criminal, perfilada ya en 1876, se encontraba asociada a una patología psiquiátrica caracterizada por la obtención de placer mediante el sufrimiento ajeno, imaginado o real (Lombroso, 1876). Las características de esta psicopatología se encontrarían, así, cercanas al concepto de "sadismo" - desarrollado diez años después por Krafft-Ebing en la que fue la obra fundadora de la sexología occidental- dentro de la categoría de "perversión sexual" (Krafft-Ebing, 1933). Al respecto, ambos autores confluyeron en el reconocimiento de la existencia de una función natural del instinto sexual basada en la reproducción de la especie, algo asumido 
de forma axiomática por la comunidad científica de finales del siglo XIX (Davidson, 2004), incluyendo al sadismo y al amor sanguinario como anomalías psíquicas exclusivamente masculinas, que podían materializarse, o no, en la comisión de agresiones sexuales de distinta índole.

Junto con las categorías psicopatológicas descritas, la etiología de las agresiones sexuales masculinas apareció también enmarcada dentro de una teoría del instinto, articulada, en términos evolutivos, sobre supuestas características esenciales a la propia naturaleza varonil. Así, mientras que Krafft-Ebing reconoció en el "hombre primitivo" una "natural" crueldad, y en el sadismo una "intensificación patológica del carácter sexual masculino", dibujado como naturalmente agresivo, frente a la "timidez natural y la modestia" femenina (Krafft-Ebing, 1933, pp. 53 y 85), Lombroso, mediante una peculiar interpretación de la selección sexual darwiniana, interpretó el gusto por el erotismo y la violencia como parte de los caracteres sexuales secundarios masculinos. La violencia sexual se naturalizó, de esta manera, como parte de una herencia evolutiva, originada en las sociedades "primitivas" en las que los varones accederían sexualmente a los cuerpos de las mujeres, venciendo su renitencia mediante el uso de la fuerza. De acuerdo con esta perspectiva, la mayor parte de las agresiones serían obra de violadores "ocasionales", individuos fisiológicamente normales, cuya potencial agresividad sexual se habría visto estimulada por determinadas circunstancias ambientales.

\section{LA VIOLACIÓN COMO ANORMALIDAD INSTINTIVA Y DEGENERACIÓN PERVERSA}

Ya en la primera sistematización médico-legal nacional, publicada en 1900 por el profesor titular de la cátedra de Higiene y Medicina Legal de la Facultad de Medicina de la Universidad de Chile, el doctor Federico Puga Borne, las perversiones sexuales -despojadas solo parcialmente de las connotaciones orgánico-anatómicas que habían tenido en el lombrosianismo²- aparecieron conceptualizadas como "estigmas psíquicos" (Puga, 1900, p. 599).

\footnotetext{
${ }^{2}$ Este autor consideraba que realizar el examen somático del acusado era fundamental para determinar su responsabilidad penal, afirmando que la "fisonomía general" era "el reflejo del estado mental" del individuo (Puga, 1900, p. 578). Este determinismo biológico, centrado en la identificación más o menos directa entre rasgos somáticos y aspectos mentales se afincó en la práctica psiquiátrica chilena desde finales del siglo XIX (Correa, 2012) y estuvo presente durante todo el periodo aquí contemplado (Sánchez, 2014).
} 
Comprendidas como degeneraciones heredadas o adquiridas, las perversiones causaban la ausencia de control sobre los centros sensitivos, originando una manifestación del instinto sexual "en toda su intensidad", junto con la reclamación "imperiosa" de su satisfacción. Dentro de este amplio conjunto de enfermedades mentales, si bien -como ya hicieran Krafft-Ebing (1933) y Lombroso (1881) - el exceso de deseo sexual en hombres y en mujeres fue contemplado, respectivamente, bajo las figuras de la satiriasis y la ninfomanía, podía relacionarse con la violación solo el sadismo, definida como una patología criminal frecuente y exclusivamente masculina, diagnosticada ante el hecho de "hallar la condición necesaria para el placer sexual en un sufrimiento de grado variable" (Puga, 1900, p. 605).

Al respecto, a través de la recopilación de casos famosos de la Medicina Legal europea, Puga Borne (1900) narró historias de individuos reincidentes y de apetito voraz, cuyos crímenes estarían atravesados por la tortura, la mutilación y el asesinato de sus víctimas, sobre todo de niños, coadyuvando, así, a dibujar la imagen del violador sádico como un ser extraordinario. Junto con este ser monstruoso, quedó perfilada también otra figura criminal, cuyo sadismo aparecía más moderado, aunque satisfecho siempre mediante prácticas peculiares, que permitirían identificar esta tipología patológica, como la ejecución de pequeños cortes, la flagelación o el pellizco de sus víctimas (Puga, 1900). La interpretación de la violencia sexual masculina como un fenómeno patológico y extraordinario estuvo acompañada por una manifiesta desconfianza de este autor hacia los frecuentes relatos presentados ante los tribunales por las víctimas de violación. Al respecto, consideraba que "ordinariamente" las mujeres parecían "no querer ceder más que a la fuerza", dando lugar, así, a falsas luchas en las que terminaban por "entregarse voluntariamente" y en las que sufrían contusiones, que podían erróneamente ser leídas en los tribunales como prueba de la comisión delictiva (Puga, 1900, pp. 79 y 86).

La categoría "perversión" operó también dentro de la vertiente jurídica de la Medicina Legal, para referir un efecto "integral" de la degeneración, concebida como proceso biológico fruto de la herencia y la interacción con el medio y como causa principal de la criminalidad (Ramírez, 1912, p. 1000). En concreto, las perversiones fueron articuladas aquí como un conjunto de "desviaciones del instinto contrarias a la reproducción" (Ramírez, 1907, p. 204), manifestadas en la tendencia orgánica e irresistible a cometer aberraciones sexuales, incluyendo formas de sadismo, concebido como "acompañar el acto sexual de otros actos de crueldad" (Muñoz, 1911, pp. 180 y 214), como consta en el material didáctico elaborado por Tomás 
Ramírez, primer profesor titular de la cátedra de Medicina Legal en la Facultad de Leyes de la Universidad de Chile, y en los apuntes de sus clases publicados por Francisco de Asís Muñoz.

La perversión como manifestación contraria a "la reproducción de la especie", interpretada como "finalidad natural del instinto sexual", se mantuvo durante todo el periodo aquí abordado, atravesando también los manuales de Medicina Legal publicados por Samuel Gajardo Contreras (1894-1969), Juez de Menores y, desde 1928, profesor de esta disciplina en la Facultad de Ciencias Jurídicas y Sociales de la Universidad de Chile (Gajardo, 1939, p. 299). Dentro de una sexualidad concebida en términos psíquicos y fisiológicos como "anormal", Gajardo concibió el sadismo como el "placer morboso de causar sufrimiento a la persona con quien se satisface el instinto sexual" (Gajardo, 1939, p. 300). Al mantener una particular cercanía a las ideas psicoanalíticas (Vetö, 2014 y Ruperthuz, 2015), Gajardo (1939) desarrolló una conceptualización dual de la perversión como estigma degenerativo y, a la vez, como extravío de la conducta, resultado de la interacción con el ambiente y susceptible de ser psicológicamente re-orientado.

Dentro de esta línea, la relación de la violencia sexual con lo anormal y lo patológico fue también articulada por el doctor Alberto Benítez Sanhueza (1889-1975), director del Instituto Médico Legal y profesor titular de esta disciplina en la Universidad de Chile entre 1928 y 1931. Para este autor, la etiología del delito, en general, residía siempre en una imbricación entre el individuo -equiparado a un "microbio"- y las condiciones ambientales adecuadas para que se revelara el crimen -asemejado a una "enfermedad infecciosa"-, sosteniendo que quienes lo perpetraban solían ser "individuos defectuosos, ociosos, degenerados por los vicios o enfermos", y reconociendo, en la degeneración, un proceso mórbido visible somáticamente, a través de la presencia de "estigmas", concebidos como "signos corporales" que influían en la conducta del individuo (Benítez, 1932, pp. 82-120). Entre las condiciones ambientales referidas, "falta de moralidad" aparecía como la causa principal de las agresiones sexuales, muy presentes entre los sectores populares, al considerar que el delito solía perpetrarse al interior de las familias por la influencia ejercida por "los dormitorios en común" frecuentes entre "las personas o familias del pueblo" (Benítez, 1932, p. 83). Junto con esta asociación, advertía, sin embargo, de la facilidad con la que se formaban las equimosis en el cuerpo de las mujeres, lo que podía dar lugar a la simulación de agresiones que no habían existido, algo frecuente en las falsas denuncias por violación, según su criterio, producidas con objeto de obtener "lucro", "chantaje" o "venganza" (Benítez, 1932, p. 86). 
La anormalidad biológica fue un factor causal presente también en la perspectiva adoptada por el médico y criminólogo Luis Cubillos ante la violación, interpretada como un delito motivado por la búsqueda de la satisfacción del instinto sexual y cometido principalmente por "psicópatas perversos" (Cubillos, 1935, p. 15), incluyendo, así, por primera vez en Chile, al violador dentro de esta categoría, heredera de la decimonónica "locura moral" (Bourke, 2009, p. 336). De acuerdo con esta perspectiva, los psicópatas sexuales eran seres perversos, anormales que no acusaban "un trastorno mental manifiesto, a excepción de un ligero déficit intelectual" (Cubillos, 1935, p. 15), pero que albergaban "deseos de degeneración y depravación sexual" (p. 15), al haberse visto alterada su esfera afectiva y moral, lo que los inclinaba a la comisión de "delitos por perversiones sexuales de toda especie" (p. 15).

En general, para Cubillos, las causas que determinaban la criminalidad estaban, en gran medida, relacionadas con la herencia morbosa y "asimilar" de los caracteres somáticos y psicológicos de los individuos degenerados (Cubillos, 1935, p. 13). Estos caracteres podían heredarse o causar alteraciones de otra especie en sus descendientes, incluyendo psicopatologías que predispusieran a la comisión criminal. Al tiempo, podían originarse por factores ambientales, como la miseria moral y económica, y por otros, a su vez, heredables, como la toxicomanía, las enfermedades venéreas o el alcoholismo, muy extendido entre el "pueblo" (Cubillos, 1935, p. 18). La consideración del alcoholismo como factor etiológico de la comisión delictiva conllevó en los relatos analizados una marcada impronta de clase, al ser esta una problemática asociada a obreros, campesinos y vagabundos, dentro de una peculiar y hegemónica percepción de la "cuestión social" (Fernández, 2000, pp. 53-55 y Vera, 2016, p. 228). Lo afirmado se relacionó también con el despliegue de explicaciones deterministas sobre la fuerte presencia del alcoholismo y el estado decadente entre los sectores populares -obreros y campesinos- interpretados ambos como causas y efectos de un deterioro orgánico que formaba "parte de un proceso de degeneración biológica que provenía de la propia irresponsabilidad moral de la familia pobre" (Sánchez, 2014, p. 398).

\section{FALTA DE INTELIGENCIA Y DELITOS SEXUALES}

Junto con la perversión, la demencia apareció desde inicios de la centuria como otro estado mental asociado a la comisión de agresiones sexuales. Al respecto, según Puga Borne (1900) los “idiotas e imbéciles", eran se- 
res "degradados" con inteligencia cuasi nula, lo que les hacía ser víctimas irresponsables, en este caso, de su "instinto genésico", tratando de cometer, por ello, brutales violaciones (p. 594). En esta misma línea, según Muñoz (1911), también la demencia senil -única enfermedad degenerativa asociada a la vejez desde inicios del siglo (Correa, 2012) - y abordada, aquí, como "atrofia completa e incurable de las facultades mentales, caracterizada por la pérdida progresiva de memoria y de voluntad", al conllevar una "excitación del sentido erótico" podía ocasionar la comisión de "delitos sexuales" (Muñoz, 1911, p. 98).

De acuerdo con esta lógica argumental, y dentro de una extendida asociación entre criminalidad y "raza", como factor biológico, según Muñoz, las agresiones sexuales a mujeres bajo la figura del "rapto" eran frecuentes entre los "indígenas araucanos", cuyo sentido moral se hallaba "pervertido por los instintos de la raza, por la falsa aplicación de sus facultades intelectuales y por costumbres inveteradas", lo que los hacía "obrar sin discernimiento" (Muñoz, 1911, pp. 173-174). La postura de Muñoz aparecía, así, cercana a la estigmatización e inferiorización racial incluida en el mestizaje asimilador, articulado desde finales del siglo XIX en los estudios etnológicos de Tomás Guevara (Vera, 2016) y que fue refutado, desde inicios del siglo XX, principalmente, desde el "nacionalismo mestizofílico" de Nicolás Palacios (Menard, 2009, p. 32), dentro de un proceso de reelaboración de la identidad nacional chilena (Subercaseaux, 2007). Este determinismo biológico del delito asociado a la raza fue visible, al menos, hasta finales del periodo aquí abordado (León, 2008).

El mantenimiento de una conceptualización de las agresiones sexuales como actos causados por los efectos del instinto, por otro lado, estuvo unido a la idea de que esta fuerza, tachada de "psiquismo elemental" por el abogado y criminólogo Hernán Brücher Encina (1919-2006), influía en la comisión de delitos sexuales en una proporción inversamente proporcional a la inteligencia presente en los sujetos (Brücher, 1944, p. 104). De acuerdo con esta percepción, la falta de delitos sexuales entre los "araucanos" presos en la Penitenciaría de Santiago -constatada empíricamente en 1948 por Israel Drapkin (1904-1992), director del Instituto de Criminología y Fidel Jeldes, antropólogo del mismo instituto- se debía a la inexistencia de denuncias, pero no a la ausencia de tal actividad delictiva, dada la "escasa inteligencia" del indígena, asimilada como axioma (Drapkin y Jeldes, 1948, p. 109).

La asociación entre debilidad mental y la comisión de agresiones sexuales quedó también evidenciada en el único ejemplo de ficha criminológica relativo al examen de un reo condenado por violación, que fue incluido 
en la Revista de ciencias penales durante estos años. Al respecto, el sujeto examinado fue clasificado como un "débil mental profundo", un "campesino pueril, bebedor, con cierto déficit del sentido moral" y "de peligrosidad mediana por su (...) madurez decreciente", con un "dimorfismo sexual poco diferenciado" y un tipo morfológico "leptosómico" (Rojas y Legarreta, 1949, pp. 190-191) ${ }^{3}$. El interés por publicar en la revista los comentarios del examen del criminal, residió en su "anormalidad" sexual y, en particular a dos factores: la edad de la víctima de su agresión, una niña de tan solo dos años de edad, y sus antecedentes penales por el delito de sodomía, su primer "acto sexual" (Rojas y Legarreta, 1949, p. 190). De acuerdo con un "paradigma médico-patologizante" de la homosexualidad, ligado a concepciones hereditaristas, degeneracionistas y pato-anatómicas (Vetö, 2018, p. 12), los elementos señalados fueron leídos como consecuencia de la interacción de un conjunto de estigmas degenerativos sobre el penado. En concreto, la agresión se atribuyó a la interacción del ambiente con la personalidad patológica del reo y factores orgánicos dependientes del funcionamiento de sus glándulas de secreción interna. De esta manera, el agresor fue tachado de "oligofrénico", "epiléptico" e "hipogonadal", interpretando que la combinación de estas tres características, -abordadas como "estigmas", imposibles de sanar- habían dado lugar a la comisión tanto de la sodomía pasada, como de la agresión sexual a la menor (Rojas y Legarreta, 1949, p. 192).

La explicación de su conducta residía en la interacción de estos factores individuales con circunstancias ambientales -centradas en el alcoholismo y en el "casi ningún éxito" del reo con las mujeres- dentro de una premisa consolidada en la criminología chilena durante la primera mitad de siglo $\mathrm{XX}$, según la cual, la falta de satisfacción de los impulsos sexuales varoniles a través de la cópula con mujeres podía conllevar el desarrollo de psicopatologías sexuales de diversa índole (Rojas y Legarreta, 1949, p. 191). El estudio concluía que, pese a su "pequeña evolución" mental, percibida por el hecho de haber "caminado hacia el sexo contrario", el haber elegido a una víctima tan joven denostaba el mantenimiento de la anormalidad patológica del reo, -concebida con base en una conducta sexual no destinada a la procreación- relacionada también con su aparente senilidad (Rojas y Legarreta, 1949, p. 191).

\footnotetext{
${ }^{3}$ Categoría empleada de acuerdo con uno de los tipos constitucionales desarrollados por el médico alemán Ernst Kretschmer (1888-1864), defensor de la vinculación entre el carácter y la constitución corporal de los individuos. Sobre su predominio en el ámbito médico chileno frente a la biotipología italiana de Nicola Pende, de gran influencia en la vecina Argentina, y su intermediación en las propuestas eugenésicas desarrolladas en Chile durante la primera mitad del siglo XX, véase Sánchez (2015).
} 


\section{AGRESIVIDAD Y DESEO EN LA CONCEPTUALIZACIÓN DEL INSTINTO MASCULINO}

La anormalidad patológica -ya fuera bajo la categoría de perversión o de psicopatología - y la falta de inteligencia como factores etiológicos de la violencia sexual masculina no lograban explicar este fenómeno en su totalidad. De esta manera, durante la primera mitad del siglo XX las percepciones aludidas convivieron con discursos tendentes a su naturalización, a través de una particular conceptualización del instinto sexual masculino como esencialmente voraz. Al respecto, la construcción de una masculinidad centrada en la agresividad y el deseo como elementos intrínsecos a la virilidad, concebida como supuesta naturaleza instintiva varonil, ya presente en el imaginario moderno -sexual y de género- hegemónico de la sociedad chilena (Hutchison, 1995; Veneros, 2012), se insertó progresivamente en los discursos criminológicos, orientados a constatar o explicar esta especie de axioma, desde la posición de autoridad otorgada por la ciencia. Como veremos, además, a pesar de su carácter transversal, esta animalización de la masculinidad no dejó de entretejerse -con mayor o menor énfasis- con viejos prejuicios clasistas, que identificaban parcialmente a los heterogéneos sectores populares con lo salvaje y lo sexualmente incontrolable (González, 2007).

Dentro de esta línea interpretativa, tras asimilar supuestas y congénitas "condiciones naturales" que diferenciaban conductualmente a los sexos, Hernán Zapata Díaz afirmó, en un artículo publicado en la Revista de ciencias penales en 1935, que los varones tenían un mayor impulso sexual y lo sentían "de una manera más violenta" que las mujeres (Zapata, 1935, p. 339). De esta manera, el "sello distintivo de los caracteres masculinos" era su natural "tendencia motora" hacia el esfuerzo violento, lo que se manifestaba en diversas formas de su actividad, "desde las creaciones de los hombres de genio hasta las preferencias delictivas de los criminales" (Zapata, 1935, p. 347). Para Zapata resultaba "comprensible" que abundaran más los "raptos y las violencias" entre los varones pese a existir también mujeres culpables de estos delitos en los establecimientos penales, algo tachado de "indecente y hasta un poco asombroso" por este autor (Zapata, 1935, p. 343). Esta misma lógica argumentativa estuvo presente en la conferencia impartida ante los miembros del Rotary Club en 1935 por el juez de letras de Temuco, Armando Vergara Lebrún. Según el magistrado, la falta de satisfacción en los varones de los "mandatos imperativos de su organismo sexual" se encontraba detrás del incremento de las agresiones a muchachas 
"aún acomodadas", registradas en Coquimbo durante el cierre de las casas de prostitución con la implantación de la "Ley Long" y perpetradas en su mayoría por forasteros, marineros o comerciantes ambulantes, ante el cierre de "locales autorizados para satisfacer sus apetitos" (Vergara, 1936, p. $256)^{4}$.

¿A qué se debía esta dicotómica conformación de los sexos? De acuerdo con una particular tendencia evolucionista, articulada en torno a la preponderancia de los procesos evolutivos en el cuerpo y en la conducta humana, y que parecía ganar cada vez más adeptos en el ámbito médico legal y criminológico internacional (Bourke, 2009), la imbricación entre agresividad y deseo sexual masculino era un vestigio de su distintiva naturaleza primitiva. Al respecto, en atención a las explicaciones otorgadas en los apuntes de Medicina Legal confeccionados en 1923 por Alfredo Grünberg Smith, jefe de trabajos prácticos en el Laboratorio Botánico de la Universidad de Chile, mientras que para la mujer resultaba "natural ser sometida al hombre", la "crueldad sexual varonil" formaba parte de su naturaleza instintiva primitiva (Grünberg, 1923, p. 62). Radicado como un "germen" en su cerebro y su sistema nervioso, este factor se exaltaba en circunstancias extremas, como las guerras, explicando, de esta manera, la frecuencia con la que la "soldadesca" violaba a las mujeres al invadir una ciudad (Grünberg, 1923, p. 62).

\section{LA EVOLUCIÓN COMO FACTOR EXPLICATIVO: WALDEMAR COUTTS Y LA INEVITABLE TIRANÍA SEXUAL}

Especialmente relevante en el estudio del instinto sexual y su relación con la comisión delictiva, dentro de los parámetros evolucionistas aludidos, fue la obra del doctor Waldemar Coutts (1895-1959), impulsor de las populares campañas de educación sexual y prevención de las enfermedades venéreas que tuvieron lugar desde la década de los años veinte- desde su puesto de jefe de la División de Higiene Social de la Dirección General de Sanidad-, además de promotor y portavoz del pensamiento eugénico chileno en el contexto panamericano (Labarca, 2008; Vetö, 2014 y Sánchez, 2018). Su temprana y particular relación con el evolucionismo condujo a Coutts a

\footnotetext{
${ }^{4}$ El Código Long, implantado en Chile en 1925 como resultado de la influencia de la deriva abolicionista internacional, de acuerdo con las doctrinas internacionales de la trata de blancas y de la explotación sexual, prohibió el ejercicio de la prostitución en todo el país hasta 1931, relegando el ejercicio de esta actividad a la clandestinidad (Gálvez, 2018, p. 292).
} 
querer explicar la conducta sexual humana en términos de darwinismo social y con base en un determinismo biológico, articulado sobre el instinto sexual, concebido como una "tiranía" que condenaba al ser humano a una lucha diaria por la conservación y la perpetuación de su especie (Sánchez, 2018, pp. 114-115). El imperativo de la selección natural sobre la vida humana aparecía, así, como factor explicativo de la agresividad y el espíritu combativo masculino, solo parcialmente contrarrestados por la moral civilizatoria y la vida moderna, causantes, al tiempo, de una excitación sexual excesiva y de una cobardía que conducían a la comisión de acciones delictivas y a la degradación de la especie (Sánchez, 2018).

La publicación en 1929 de la obra "El deseo de matar y el instinto sexual" supuso la culminación de su propuesta sobre la etiología de las agresiones sexuales, articulada ya en dos publicaciones previas del autor (Coutts, 1926; Coutts, 1928). Al respecto, Coutts desarrolló aquí una interpretación fisiológica de la conducta humana basada en su animalización, sosteniendo que, de acuerdo con las funciones genitales del instinto, existía una "reacción específica psicosexual de cada sexo" (Coutts, 1929, p. 51). Dentro de un relato -imaginado, pero que se pretendía veraz- sobre los primeros seres humanos, el espíritu combativo aludido, en los varones primitivos operaría también como medio para "apoderarse" de las mujeres (Coutts, 1929, pp. 22-24), de acuerdo con un deseo sexual varonil concebido como un elemento voraz que "aguijoneaba" y hacía de la violencia una reacción lógica ante la imposibilidad de acceder a los cuerpos femeninos (Coutts, 1929, p. 22).

La interacción con el ambiente, por otro lado, podía provocar exaltaciones en este instinto, causando, así, un "hipergenitalismo psíquico". Según Coutts, cuando este se adquiría de forma temporaria, a causa de un ambiente pernicioso, como eran la vida urbana moderna o la ingesta de alcohol -especialmente entre la "clase baja", cercana, por sus formas de vida, al "cavernario"-, podía someter al varón a la exaltación de un "sadismo fisiológico", comprendido como el gusto por el dolor ajeno (Coutts, 1929, p. 57). Sin embargo, además de esta alteración patológica, el hipergenitalismo podía ser también constitucional en los varones, haciendo de estos "machos perfectos, activos e infatigables para la lucha y el trabajo" (Coutts, 1929, p. 55). De esta manera, el "individuo normal", "cuando se encontraba a solas con la hembra", en una situación de "excitación sexual", podía tratar "de vencer por la fuerza la resistencia que a sus deseos" oponía la mujer, "montando en cólera" por la acción que sobre su voluntad ejercería el instinto (Coutts, 1929, p. 79). 
Las agresiones sexuales masculinas producidas sobre mujeres eran, según esta lectura, una consecuencia lógica del funcionamiento fisiológico del instinto sexual, contrarrestable solo por el efecto de la cultura, algo frente a lo que Coutts mostró una posición ambigua. Al formar parte de una selección natural deseable, dentro del pensamiento darwinista social y eugénico articulado por este autor (Sánchez, 2018), la incidencia de la civilización ante este instinto podía atentar contra algunos de los necesarios procesos de selección y perfeccionamiento de la especie humana, dentro de los cuales se encontraban las propias guerras, conflictos en los que subyacía siempre el aspecto sexual como un incentivo primordial (Coutts, 1929).

De acuerdo con este axioma, de la misma manera que "los primeros pobladores de la tierra" luchaban con objeto de "conquistar hembras", las "acciones victoriosas" contemporáneas también precedían a "orgías y festines" que actuaban como motor en el conflicto (Couts, 1929, p. 106). La posición de Coutts al respecto era rotunda al afirmar:

el barniz superficial de la cultura desaparece, aun de los cerebros privilegiados, ante la sonrisa seductora de las cortesanas o la promesa de la libido albergado en el cuerpo de las mujeres, que encarna el triunfo de las fuerzas de ocupación. (Coutts, 1929, p. 106)

Si las guerras eran necesarias y la violación su principal causa, dentro de esta lógica, las agresiones sexuales no solo aparecían como una consecuencia natural e inevitable del funcionamiento fisiológico del ser humano, sino también como un elemento deseable.

\section{LA EDUCACIÓN COMO ORIENTACIÓN DEL INSTINTO. NATURALEZA Y CULTURA EN LAS POSTURAS DE LUIS COUSIÑO MAC-IVER Y SAMUEL GAJARDO}

Dentro de esta misma línea evolucionista, pero con distintos encuadres y derivas se posicionaron tanto el abogado, criminólogo, profesor de Medicina Legal y presidente del Instituto de Ciencias Penales, Luis Cousiño MacIver (1903-1995), como el profesor y juez de Menores Samuel Gajardo.

Cousiño (1944) fue crítico con los planteamientos bio-tipológicos y constitucionalistas, basados en la determinación de la herencia como factor etiológico del comportamiento humano y, en especial, de la comisión delictiva. Pese a reconocer la relevancia de los aportes del lombrosionismo y la existencia del criminal nato, para Cousiño (1944) la representación de 
esta tipología era extremadamente baja entre los criminales, afirmando -de la misma manera que lo hizo Lombroso en su momento- que la mayor parte de los delitos, interpretados como actos de conducta, eran cometidos por seres humanos comunes.

A diferencia de los defensores del neolamarckismo imperante, según este autor los mal llamados "hábitos adquiridos", dentro de los que figuraba la sociabilidad humana, eran productos culturales, no transmitibles por herencia, por lo que esta debía promoverse en cada generación (Cousiño, 1944, p. 307)5. El ser humano aparecía, así, como un ser "primario, primitivo, asocial, egoísta, instintivo, emocional y agresivo", pero con capacidad de adaptación al medio (Cousiño, 1944, p. 307).

Dentro de esta interpretación, el varón operaba guiado, principalmente, por el instinto de reproducción, concebido como una fuerza dependiente de la imbricación de factores "neuro-psíquicos" y "neuro-endocrinos" o fisiológicos (Cousiño, 1941, p. 254), cuya insatisfacción era una "tragedia" mucho más fuerte en ellos que en las mujeres (Cousiño, 1944, p. 305). De acuerdo con las apreciaciones de Gregorio Marañón, Cousiño interpretaba la sexualidad como una escala, dentro de la cual existía una relación jerárquica, donde lo masculino y viril era lo sexualmente activo y superaba a lo femenino, concebido como una "anestesia del instinto" (Cousiño, 1941, pp. 254). El instinto sexual operaba, de esta manera, como un motor de la acción masculina, determinando su papel activo en todos los aspectos de la vida humana, incluyendo el trabajo o la búsqueda del "sexo contrario", que, según esta interpretación, se mostraría receptivo y pasivo en su juventud y volcado en su edad adulta hacia la maternidad, considerada como una fuerza antinómica de la sexualidad en las mujeres (Cousiño, 1941, p. 257).

De acuerdo con lo afirmado y mediante la referencia a la idealización de un pasado pre-histórico, la agresividad -dibujada como una cualidad característica del varón "primitivo"- se traducía irremediablemente en una violencia sexual dirigida contra las mujeres solo bajo circunstancias extremas de privaciones, en un marco de "lucha entre los propios asociados por la presa conquistada” (Cousiño, 1944, p. 306). Bajo esta premisa, por tanto, la voluntad varonil estaría sujeta a un instinto de reproducción que, ante la imposibilidad de acceder al cuerpo de las mujeres, empujaría a los individuos a emplear la fuerza y a violar. Con base en los trabajos psicoanalíticos

\footnotetext{
${ }^{5}$ El evolucionismo neolamarckista -predominante en el contexto latinoamericano del siglo XIX y defensor de la heredabilidad de los caracteres adquiridos- estuvo imbricado en Chile con los planteamientos pesimistas del degeneracionismo (Sánchez, 2014).
} 
de Franz Alexander y de Hugo Staub, para Cousiño todo varón era un criminal innato que, solo por medio del aprendizaje, podía desviar sus naturales y congénitos instintos motores criminales hacia otros fines socialmente inocuos (Cousiño, 1944).

Por su parte, Samuel Gajardo, a diferencia de Cousiño y de Coutts, defensores del determinismo sexual, concibió el instinto como "una ley biológica" ligada a la secreción hormonal y a estímulos psíquicos, que actuaba en el individuo desde su inconsciente, pero que aparecía condicionado también por su capacidad reflexiva. De esta manera, si bien aparecía dibujado como una "fuerza tiránica" en los varones y como "más atenuado" y "de menor intensidad" en las mujeres (Gajardo, 1939, p. 242), este profesor de Medicina Legal dejó abierta la posibilidad de que el supuestamente constatable "carácter pasivo" de la mujer en la actuación sexual fuese una consecuencia directa de la acción de las costumbres, distanciándose, en este sentido, del determinismo biológico imperante (Gajardo, 1939, p. 460). Pese a lo afirmado, en atención a la violación, paradójicamente, Gajardo siguió conceptualizando este delito como un acto egoísta, encaminado a satisfacer las necesidades biológicas del organismo, un "ultraje", en términos morales, que hacía retroceder al hombre a un supuesto estado primitivo (Gajardo, 1939, p. 506), en que, siendo la violencia la norma común de las acciones, el "troglodita", "aguijoneado por el instinto sexual" derribaba a la mujer para satisfacer sus deseos (Gajardo, 1928, pp. 15-16).

$\mathrm{Al}$ reconocer las agresiones sexuales como el resultado de la interacción de este supuesto instinto primitivo con el ambiente, de la misma manera que factores como las guerras actuaban como elementos "regresivos" que desmoralizaban al hombre y favorecían su comisión (Gajardo, 1928, p. 39), una educación adecuada permitía orientar la satisfacción de este instinto tanto hacia el ámbito legítimo de la reproducción como hacia su sublimación (Gajardo, 1939). Lo afirmado sirvió al profesor para alejar la violación de los estratos socioeconómicamente más elevados de la sociedad, a los que les reconocía una mayor "conciencia moral" que la "clase proletaria", cuya mentalidad y hábitos probaban que no sentía "la menor repugnancia por numerosos actos deleznables de crueldad" (Gajardo, 1928, p. 32). Las agresiones sexuales aparecían, así, dibujadas por el autor como actos perpetrados "casi siempre por hombres incultos, como bandoleros y asesinos", concibiendo la violación como un delito raro, frecuentemente denunciado por "muchachas" que, después de haberse "entregado voluntariamente", alegaban haber sido violadas para "justificar su conducta" (Gajardo, 1939, p. 506). 


\section{CONCLUSIONES}

La entronización de la Criminología y la Medicina Legal como campos científicos y sistemas de significación durante la primera mitad del siglo $\mathrm{XX}$ supuso su validación como centros de producción de un conocimiento pretendidamente neutro, lugar desde el que coadyuvaron a la construcción científica del cuerpo sexuado mediante la conformación de la violación, como categoría sociocultural y mandato de género (Bourke, 2009).

Dentro del proceso aludido, como hemos tratado de enfatizar en este artículo, los trabajos analizados confluyeron desde su heterogeneidad en el afán por definir y comprender las agresiones masculinas a través del funcionamiento del instinto sexual -asimilado como impulso o fuerza- dentro de la construcción de una normalidad, mediante la creación de esquemas categoriales anormales -concebidos como factores congénitos, adquiridos o como resultado de la combinación de elementos ambientales o heredadosy dando una mayor importancia a los factores físicos o psíquicos, según el caso. De esta manera, el instinto quedó ideológicamente conceptualizado como un impulso naturalmente manifestado en la atracción hacia el sexo contrario y funcionalmente dirigido hacia la reproducción, cuya intensidad conllevaría aparejada una correlacional agresividad, determinada en función del género, lo que consideramos que pudo favorecer una aceptación tácita de la violencia sexual masculina como natural e inevitable.

$\mathrm{Al}$ respecto, ante la imposibilidad de constatar empíricamente esta invisible imbricación, los autores consultados hicieron uso de la especulación o de su aceptación como premisa axiomática, de acuerdo con las dinámicas adoptadas por la tradición científica occidental desde la segunda mitad del siglo XIX (Fausto-Sterling, 2000). La reformulación de la teoría darwiniana, además, dotó a algunos de estos discursos de las herramientas argumentales necesarias para justificar la naturalización biológica de los roles sociales -estructurados bajo la asimilación de lo masculino como agresivo y activo y de lo femenino como receptor y pasivo, desde una perspectiva funcional y evolucionista, dentro de la cual la guerra fue asimilada como sinónimo de violación, contribuyendo, así, a la promoción de una asociación inserta, aun hoy, en el imaginario colectivo y actualmente en deconstrucción (Maldonado, 2019).

Las apreciaciones etiológicas de la mayor parte de los autores contemplados estuvieron imbricadas con una serie de prejuicios y estereotipos en torno a la comisión de estos delitos, contribuyendo, así, a dibujar la imagen del violador como un ser perteneciente a una otredad popular y, en ocasio- 
nes, racializada. La percepción, compartida por algunos autores, de que se trataba de un delito sobredimensionado, además, se tradujo en una visible y extendida preocupación por proteger a los varones de las supuestamente abundantes falsas acusaciones femeninas, coadyuvando a la relegación de este fenómeno a una posición secundaria y prescindible dentro de las áreas abordadas.

\section{REFERENCIAS}

Antaki, C. y Condor, S. (2000). Cognición social y discurso. En T. A. Van Dijk (ed.). El discurso como estructura y proceso (pp. 453-489). Barcelona: Gedisa.

Archimio, E, (2018). Para una genealogía del violador. Prácticas penales, discursos médicos, psiquiátricos y criminológicos en la configuración del agresor sexual en Argentina en la primera mitad del siglo XX. Sexualidad, salud y sociedad, 28, 30-50.

Beccalossi, C. (2012). Female Sexual Inversion. Same-Sex Desires in Italian and British Sexology, c.1870-1920. New York: Palgrave Macmillan.

Benítez, A. (1932). Manual práctico de medicina legal: adaptado al personal de los diferentes servicios de policías de Chile. Santiago: Talleres San Vicente.

Brücher, H. (1944). Estudio de la personalidad de los delincuentes chilenos. Santiago: La Salle.

Bourdieu, P. (2008). Los usos sociales de la ciencia. Buenos Aires: Nueva Visión.

Bourke, J. (2009). Los violadores. Historia del estupro de 1860 a nuestros días. Barcelona: Crítica.

Bowler, P. J. y Morus, Iwan R. (2005). Making Modern Science: a Historical Survey. Chicago: The University of Chicago Press.

Butler, J. (2007). El género en disputa. El feminismo y la subversión de la identidad ( $3^{\mathrm{a}}$ ed.). Barcelona: Paidós.

Campos, R. (2013). La construcción del sujeto peligroso en España (18801936). El papel de la psiquiatría y la criminología. Asclepio LXV(2), 1-13. http://dx.doi.org/10.3989/asclepio.2013.17

Carnevali, R. (2008). La ciencia penal italiana y su influencia en Chile. Política Criminal IV(6), 1-19. https://papers.ssrn.com/sol3/papers.cfm?abstract_ id $=2711416$

Correa, M. J. (2012). Cuerpo y demencia. La fisonomía de la incapacidad en Santiago de Chile (1855-1900). Historia Crítica, 46, 88-109.

Cousiño, L. (1941). Breve curso de medicina legal: para el uso de los estudiantes del $5^{\circ}$ año de las Escuelas de Derecho. Santiago: Taller Politécnico de Menores "Alcibíades Vicencio".

Cousiño, L. (1944). La interpretación bio-psicológica del delito. Revista de ciencias penales, VII, 301-314. 
Coutts, W. (1926). El Instinto sexual y la vida contemporánea. Su influencia en los actos delictuosos. Buenos Aires: Imp. de la Penitenciada Nacional.

Coutts, W. (1928). Delito instintivo o habitual y delito razonado. Santiago: Imprenta Chile.

Coutts, W. (1929). El deseo de matar y el instinto sexual. Madrid: Javier Morata.

Cubillos, L. (1935). El problema médico social y legal de nuestra delincuencia. Revista Detective II(17), 10-24.

Davidson, A. (2004). La aparición de la sexualidad: la epistemología histórica y la formación de conceptos. Barcelona: Alpha Decay.

Del Olmo, R. (2010). América Latina y su criminología (4ªed.). Ciudad de México: Siglo XXI.

Drapkin, I. y Jeldes, F. (1948). Algunas consideraciones acerca de la criminalidad entre los araucanos. Revista de ciencias penales, 10, 106-109.

Durán, M. (2014). Género, cuerpo, gimnasia y sexualidad en los manuales educacionales higienistas y eugenésicos en Chile, 1870-1938. Revista de Historia Social y de las Mentalidades XVIII(1), 35-58.

Fausto-Sterling, A. (2000). Sexing the Body: Gender Politics and the Construction of Sexuality. Nueva York: Basic Books.

Fernández, M. (2000). Pobres, borrachos, violentos y libres: notas para la reconstrucción de identidades masculinas populares en el siglo XIX. En J. Olavarría y R. Parrini (eds.). Masculinidad/ Identidad, sexualidad y familia (pp. 47-58). Santiago: FLACSO-UAHC.

Gajardo, S. (1928). La génesis biológica del delito y la delincuencia de menores. Santiago: Nascimento.

Gajardo, S. (1939). Medicina legal: normas para la enseñanza jurídica del ramo en las Universidades. Santiago: Nascimento.

Gálvez, A. C. (2018). Prostitución y trata de blancas: El discurso internacional del victimismo (Chile, 1934). História Unisinos 22(2), 290-302.

Gibson, M. y Rafter, N. H. (2006). Introduction. En C. Lombroso, Criminal man (pp. 1-41). Durham y Londres: Duke University Press.

González, C. (2007). La sexualidad como representación y las representaciones de la sexualidad. La construcción del sodomita en Chile, 1880-1910. En A. Araya, A. Candina, y C. Cussen (eds.). Del Nuevo al Viejo Mundo: mentalidades y representaciones desde América (pp. 184-199). Santiago: Fondo de Publicaciones Americanistas, Universidad de Chile.

Grünberg, A. (1923). Apuntes de medicina legal y enfermedades mentales. Santiago: Imprenta Universitaria.

Huertas, R. (1990). El concepto de "perversión" sexual en la medicina positivista. Asclepio II(42), 89-99. https://doi.org/10.3989/asclepio.1990.v42.2.559

Hutchison, E. (1995). La defensa de las "hijas del pueblo": género y política obrera a principios de siglo. En L. Godoy, E. Hutchison, K. Rosemblatt y M. S. Zárate (eds.). Disciplina y desacato: construcción de Identidad en Chile, siglos XIX y XX (pp. 125-138). Santiago: Ediciones SUR, CEDEM. 
Krafft-Ebing, R. (1933). Psychopathia Sexualis with especial reference to the antipathic Sexual Instinct (12a ed.). Brooklyn: Physicians and Surgeon Book Company.

Labarca, C. (2008). Todo lo que usted debe saber sobre las enfermedades venéreas. Las primeras campañas de educación sexual estatales entre 1927 y 1938. En M. S. Zárate (ed.). Por la salud del cuerpo. Historia y políticas sanitarias en Chile (pp. 81-129). Santiago: Ediciones Universidad Alberto Hurtado.

León, M. A. (2008). Extirpando el "Jermen del mal”: visiones y teorías criminológicas en Chile contemporáneo (1911-1960). Cuadernos de Historia, 28, 81-113.

León, M. A. (2018). Pesquisas visuales: representación e identificación criminal a través de revistas policiales chilenas (1934-1961). Estudos Ibero-Americanos, $\operatorname{ILIV}(1), 138-148$.

Lombroso, C. (1876). L'uomo delinquente studiato in rapporto alla antropologia, alla medicina legale ed alle discipline carcerarie. Milán: Ulrico Hoepli.

Lombroso, C. (1881). Amori nei pazzi. Archivio di Psichiatria Antropologia Criminale e Scienze Penali per servire allo studio dell' uomo alienato e delinquente, 2, 1-32.

Maldonado, J. (2019). Violencia política sexual: una conceptualización necesaria. Revista Nomadías, 27, 143-166.

Menard, A. (2009). Pudor y representación. La raza mapuche, la desnudez y el disfraz. Aisthesis, 46, 15-38.

Muñoz, F. (1911). Estudios sobre Antropología Jurídica (Medicina legal): obra escrita con arreglo al programa universitario formado para el Curso de Derecho. Santiago: Imprenta y Encuadernación Chile.

Palafox, A. (2019). Biología y género en la etiología de la violencia sexual. Reflexiones desde la historia de la Escuela de Antropología Criminal Italiana (1876-1903). Diálogos: investigación y sociedad. Reflexiones desde la historia y la historia del arte (pp. 83-112). Santiago: RIL; Universidad Autónoma de Chile.

Palafox, A. (2020). La Medicina Legal y el delito de violación en Chile (18751922). Dynamis XL(1), 125-146.

Puga, F. (1900). Compendio de Medicina Legal adaptado a la legislación chilena. Santiago: Imprenta Cervantes.

Ramírez, T. (1907). Apuntes de medicina legal. Santiago: Imprenta y Encuadernación Chile.

Ramírez, T. (1912). Contribución al estudio de la previsión de la delincuencia. Anales de Chile, 130, 983-1015.

Rojas, G. y Legarreta, A. (1949). Fichas criminológicas n. 1675. Revista de ciencias penales, 11, 189-192.

Ruperthuz, M. (2015). El "retorno de lo reprimido": el papel de la sexualidad en la recepción del psicoanálisis en el círculo médico chileno, 1910-1940. História, Ciências, Saúde XXII(4), 1173-1197. 
Sánchez, M. (2014). La teoría de la degeneración en Chile (1892-1915). Historia, 47, 375-400.

Sánchez, M. (2015). Chile y Argentina en el escenario eugénico de la primera mitad del siglo XX. Santiago: Universidad de Chile.

Sánchez, M. (2018). Sexo, eugenesia y política: Waldemar Coutts (Chile, 18951959). Revista de Historia XXV(1), 109-130.

Subercaseaux, B. (2007). Historia de las ideas y de la cultura en Chile. Santiago: Editorial Universitaria.

Veneros, D. (2012). “La virtud bajo amenaza”. La Ciudad de Santiago y las obreras fabriles. 1880-1930. Contextos, 28, 155-170.

Vera, A. (2016). La superioridad moral de la mujer: sobre la norma racializada de la femineidad en Chile. Historia y Política, 36, 211-240.

Vergara, A. (1936). Relaciones sexuales de los penados. Revista de ciencias penales, II, 240-258.

Vetö, S. (2014). Psicoanálisis, higienismo y eugenesia: educación sexual en Chile, 1930-1940. Nuevo Mundo, Mundos Nuevos, 1-22. Doi: https://doi. org/10.4000/nuevomundo.66920

Vetö, S. (2015). Psicoanálisis y eugenesia en el campo criminológico de la década de 1930 y 1940. Indagaciones a partir de algunos escritos del juez de Menores Samuel Gajardo. En C. Leyton, M. Sánchez, y C. Palacios. El bulevar de los pobres. Racismo científico, higiene y eugenesia, siglos XIX y XX (pp. 163-193). Santiago: Ocholibros.

Vetö, S. (2018). Homosexualidad masculina y examinación médica en la Casa de Menores de Santiago, 1929-1942. Revista Historia y Justicia, 10, 1-31. https://doi.org/10.4000/rhj.1286

Zapata, H. (1935). Criminalidad de hombres y mujeres. Proporciones y preferencias. Revista de ciencias penales, I, 333-348. 